\title{
Quantitative Evidence of Students' Use of Social Networks and Social Categorization When Self-Selecting Teams
}

\begin{abstract}
This article presents two studies aimed at understanding consequences of giving students complete decision-making authority to select team members for a team assignment. Study 1 concludes that students place a high level of importance on cognitively categorizing their classmates as those to approach and avoid when self-selecting teams, and they put forth a good deal of effort to actually approach some classmates and avoid others. The approach category forms for most students as they develop a team assignment social network comprised of classmates who are highly trusted and believed to be high in trustworthiness. Study 2 finds evidence that, in the absence of network members and prior knowledge of each other, students use social cues (style of dress) to cognitively categorize classmates and make inferences about their trustworthiness based on the category in which they are placed. Study 2 also finds that style of dress influences students' trust in their classmates, preference for who they want on their team, and effort they would put forth to approach some classmates and avoid others. Implications and opportunities for future research are discussed.
\end{abstract}




\section{Introduction}

Pedagogical methods have long been considered a set of stimuli placed in students' environment to influence their cognition, affect, and behavior (Thorndike, 1906). The design of methods such as team assignments should then be guided by an understanding of their consequences for students across all three dimensions of cognition, affect, and behavior. Among an instructor's team assignment design-related decisions is the process through which teams are formed. And to form teams an instructor has to first determine who will have decision-making authority for who works with whom. The fundamental issue is that published literature is quite disparate regarding where decision-making authority should fall.

Some authors explain that instructors should decide who works with whom (e.g., Blowers, 2003; Muller, 1989), while others propose ways for instructors and students to share decision-making (e.g., Matta, Luce, \& Ciavarro, 2010). A third group of authors advocates giving students complete decision-making authority to form their own teams (e.g., Chapman, Meuter, Toy, \& Wright, 2006), and arguments for doing so include that students are best placed to "engineer" their teams (Huxham \& Land, 2000) since they likely have greater insight into the characteristics of potential team members than instructors (Seethamraju \& Borman, 2009).

These different perspectives on how teams should be formed stem, at least in part, from a disparate and limited understanding of the actual consequences for students of the different approaches. For example, authors who advocate giving students complete decision-making authority have linked the approach to positive consequences such as higher initial team cohesiveness (Mello, 1993) and greater student satisfaction with team experiences (Chapman et al., 2006). At the same time, other authors have reported that self-selection can lead to unintended consequences of a remainder problem (Bacon, Stewart, \& Anderson, 2001) and inter- 
team inequity in project-relevant abilities (Bacon, Stewart, \& Stewart-Belle, 1998). In addition, recent exploratory qualitative studies (Neu, 2012; 2015) indicate that students approach selfselection by forming, and selecting members from, a social network of trustworthy team members. And, in the absence of trustworthy network members, students appear to use social cues to form initial beliefs about their classmates' trustworthiness and then behave differently towards them based on those beliefs.

The initial insights by Neu $(2012 ; 2015)$ were the main motivation for this research, the overarching purpose of which was to provide quantitative evidence that clarifies and confirms students' reliance on social networks and social cues in the self-selection process. More specifically, this research first set out to answer two general questions on which the relevance of the research is based. That is, 1) How important is it to students to cognitively categorize classmates as those to approach and those to avoid when self-selecting teams? And, 2) How much effort do students normally put forth to approach some classmates and avoid others when self-selecting teams? Given that cognitive categorization of classmates is important and students do put forth high effort to approach some classmates and avoid others, attention turned to questions pertaining to actual cognitive and behavioral processes: 3) Do students form over time a social network of preferred team members? 4) Are network members thought to be higher in trust and trustworthiness than other, non-network classmates? And, 5) Do students team up with network members when asked to self-select their teams? Finally, this research investigated the self-selection process in the absence of network members or other prior knowledge about classmates. That is, do social cues influence students' 6) beliefs about their classmates' trustworthiness, 7) trust in their classmates, 8) preference for who they want or not want as a 
teammate, and 9) intentions to approach some classmates and avoid others when self-selecting teams?

The remainder of this article covers a two-part study and is organized as follows. First, the article focuses on research questions $1-5$ with background literature, methodology, results, and discussion for Study 1. Then, drawing on results of Study 1, attention turns to research questions 6 - 9 with the background, hypotheses, methods, results, and a discussion for Study 2. The article ends with a conclusion and limitations of the research.

\section{Study 1}

\section{Background}

Published literature offers three perspectives on organizing students for team assignments. A fundamental difference among the perspectives is in who has decision making authority during team formation. Some authors have concluded that instructors should make decisions about who works with whom (Feichtner \& Davis, 1985). When they do assume responsibility, instructors often assign students to teams randomly which can, due to chance, lead to unintended consequences such as inequity in project-relevant resources and collective academic abilities among teams, and a lack of demographic diversity within teams (Bacon et al., 1998). Alternatively, to avoid the unintended consequences of random assignment, instructors can assigned students to achieve a desired mix of project relevant resources and level of diversity within teams, and an equitable allocation of resources across teams (e.g, Bacon et al., 1998; Blowers, 2003; Muller 1989; Scott, Bisland, Tichenor, \& Cross, 1994).

The second perspective is an approach by which instructors share decision-making authority with students. Basically, students first identify classmates with whom they want to work, and then instructors make the final decisions by assigning students to teams while trying to 
accommodate preferences. The third perspective is that instructors give students complete decision-making authority to self-select their team members. While self-selection has been linked to some positive outcomes such as early team cohesiveness (Mello, 1993) and satisfaction with overall team performance (Connerley \& Mael, 2001), the approach has been linked to negative consequences including the "remainder" problem which occurs when students are left without a team after teams have been formed (Bacon et al., 2001), and a lack of needed projectrelevant resources or desired level of diversity (Jalajas \& Sutton, 1984-1985).

Research suggests that self-selection is, in part, a process through which undergraduate business students form and then select members from a team assignment social network (Neu, 2012). A social network consists of a set of social entities, often called actors, and the collection of ties among them (Van den Bulte \& Wuyts, 2007). Actors can be individuals, organizations, formally defined groups, or other social units, and the actors are linked to one another by social ties representing some relationship. Network members then accrue social capital—such as access to information and other resources - by virtue of their membership in the network (Van den Bulte \& Wuyts, 2007). The degree to which benefits do accrue to network members depends on attributes of social ties. Among the attributes of social ties is trust (Van den Bulte \& Wuyts, 2007).

Trust is the "willingness of a party to be vulnerable to the actions of another party based on the expectation that the other will perform a particular action important to the trustor, irrespective of the ability to monitor or control that other party" (Mayer, Davis, \& Schoorman, 1995, p. 712). Trust is not the act of taking risk per se, but rather it is a psychological state comprising the willingness to take risk or accept vulnerability based on the behaviors of another. Vulnerability implies that there is something of importance to be lost (Boss, 1978; Zand, 1972). 
In other words, risk creates the opportunity for trust, or the need for trust only arises when there is risk.

Trustworthiness, the main precursor to trust, is defined as one's beliefs about another's ability, benevolence, and integrity (Mayer et al., 1995). Ability is the "group of skills, competencies, and characteristics that enable a party to have influence within some specific domain" (Mayer et al., 1995, p. 717). Benevolence is the extent to which an individual is believed to want to do good for the trustor, and integrity involves the trustor's perception that the trustee adheres to a set of principles that that the trustor finds acceptable. While trust is a psychological state of a trustor, trustworthiness involves beliefs about the characteristics of the trustee. Beliefs about these characteristics are context dependent—one could be deemed to have the abilities needed to have a positive influence in one setting but not another. Since beliefs about trustworthiness comprise the main precursor to trust, trust is also context specific.

When students self-select team members they engage in a risk-taking behavior that indicates trust. That is, students are vulnerable to the future behaviors of classmates with whom they decide to team up. There is uncertainty about whether classmates will exhibit the behaviors of an effective team member and whether they will contribute their fair share in terms of quantity and quality of work provided. In addition, there is something important to be lost such as not achieving the grade to which one aspires or having to contribute more than one's fair of time and effort to make up for a low-performing team member (Neu 2015).

Against this backdrop Study 1 set out to investigate undergraduate business students' decision-making process when they self-select their team members. Specifically, the purpose was to first establish just how important it is to students to cognitively categorize their classmates as those with whom they do and do not want to form a team, and how much effort 
students normally put forth to approach some classmates and avoid others. Then the study focused on gaining insight into the extent to which business students develop over time a group assignment social network, and whether students in the network are more trusted and thought to be more trustworthy than classmates who are not in the network. Finally, this first study focused on the extent to which students, when asked to self-select team members, actually do or would form teams with members of their group assignment network.

\section{Methodology}

A convenience sample of 145 undergraduate business students was selected from five business

classes - two sections of Principles of Marketing, two sections of Marketing Research, and one section of Marketing Communication — taught at a university in the Southwestern US. The sample consisted of students from a variety of majors and $40 \%$ were juniors, $44 \%$ were seniors, and $16 \%$ identified their class standing as "other."

Data collection progressed through three stages that occurred in two sittings. Subjects were first asked to list all of the current students in the College of Business whom they would consider members in their group assignment network, and to select and record on the form a five-digit number. More specifically, the instruction, which was titled "Your Team Assignment Network Members," consisted of the following:

For this exercise please identify all of the current students in the College of Business at [university name] with whom you would naturally form teams for team assignments. Don't worry about the number of students you identify, just list all of those about whom you would think, "yes, if this person were in my class I would like to form a team with him/her," and he/she would think the same about you. Please enter the name of each business student below. If no other students 
come to mind, that is fine. The list of names is for your use only. You will NOT be asked to share this form with anyone including Professor [name]. You will need this form to complete remaining surveys.

Also, during the first sitting, a survey was administered to measure the subject's trust in, and beliefs about the trustworthy of, three of his or her listed members - the first, the second, and the last student listed. Trust was measured with two items selected and adapted from Mayer and Gavin (2005). The three dimensions of trustworthiness were measured with 11 items selected and adapted from Mayer and Davis (1999). More specifically, four items were used to measure beliefs about abilities, four items measured beliefs about benevolence, and three items were used to measure beliefs about integrity (indicators of trust and trustworthiness appear in Table 1 in the Appendix). All items were on a seven-point Likert-like scale and responses ranged from $1=$ strongly disagree to $7=$ strongly agree. Scale reliabilities (alpha) were ability $=.96$, benevolence $=.93$, integrity $=.90$, and trust $=.87$.

A third survey was administered during the second sitting to measure the subject's trust in, and beliefs about the trustworthiness of, three classmates not listed among his or her network members - a classmate the subject would tend to approach and ask to be part of a group, a classmate whom they would tend to avoid during team formation, and a classmate toward whom they are completely indifferent about approaching and asking to be part of a team. As an example, the specific instruction on one version of the survey stated, "Now assume that you are NOT able to team up with others listed on your Team Assignment Network Members form. Please think about a student whom you are completely indifferent about approaching and asking to be part of your assignment team, and you are indifferent about their approaching you and asking to part of a team." The same items that appeared on survey 2 were used to measure trust 
and the three dimensions of trustworthiness. This survey also included items to measure class standing, how important it is to the respondent to categorize classmates as those with whom they want to form a team or want to avoid during team formation (five-point scale from not at all to extremely important), how much effort the respondent would put forth to avoid or approach classmates (five-point scale from none to a lot), and the extent to which the respondent actually did (or would in a hypothetical situation) team up with network members.

\section{Results}

Analysis began by summarizing responses to survey items that measure the importance of categorizing classmates as those to approach or avoid (research question 1), and the effort normally put forth to approach some classmates and avoid others when forming teams (research question 2). As shown in Figure 1, cognitively categorizing classmates is important; 94\% of the respondents consider categorizing classmates as those to approach to be at least moderately, and $88 \%$ think that categorizing classmates as those to avoid is at least moderately important. In addition, $80 \%$ of the participants indicated that, during group formation, they normally put forth at least a moderate amount of effort to approach classmates with whom they want to form a team, and $60 \%$ indicated that they normally put forth at least a moderate amount of effort to avoid classmates with whom they do not want to form a team (Figure 2). 
Figure 1: Importance of Categorizing Classmates as Those to Approach and Avoid

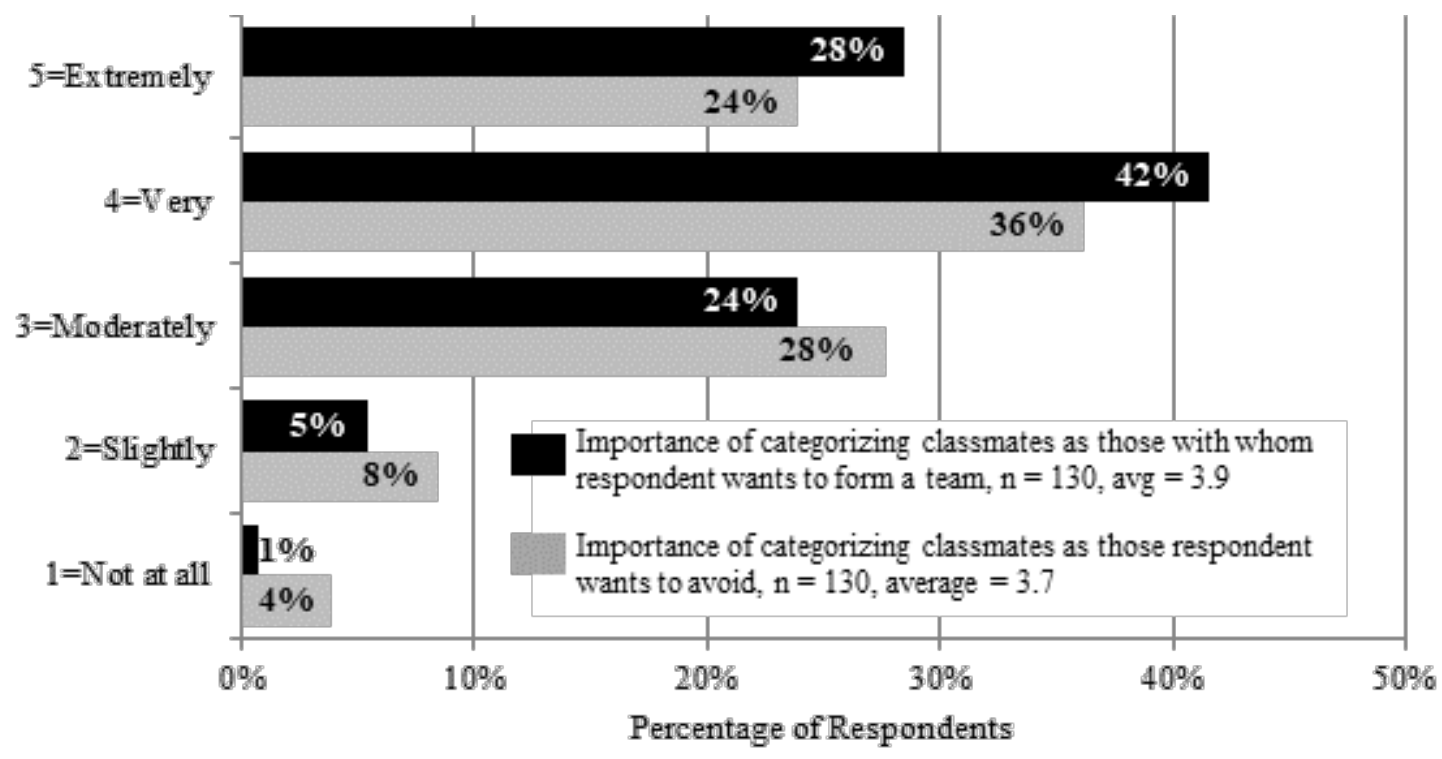

Figure 2: Effort Put Forth to Avoid and Approach Classmates

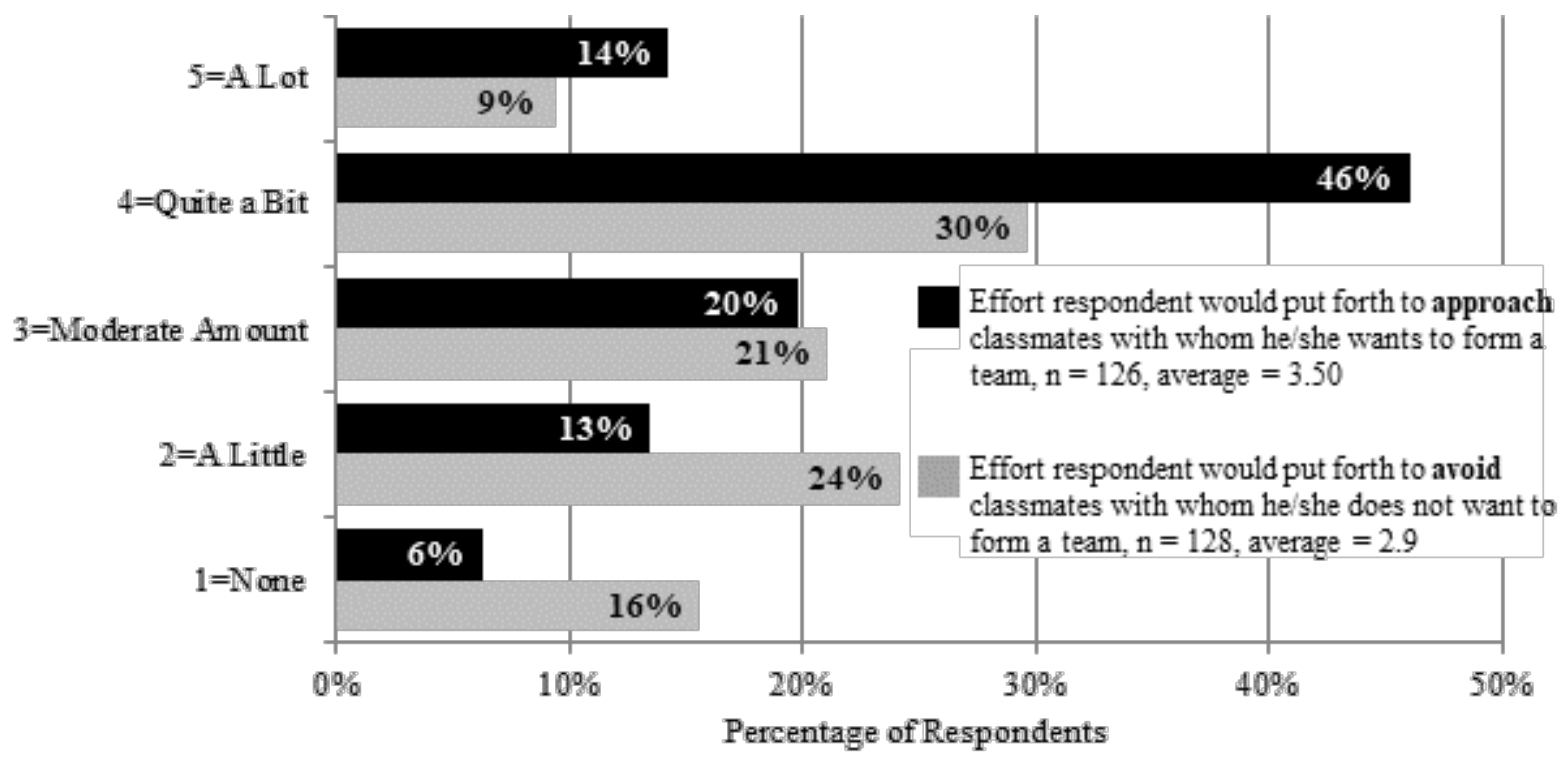

Focus then turned to research question 3 and understanding the extent to which students form over time a team assignment social network. Overall, $133(92 \%)$ of the 145 students who 
participated in the study listed one or more members in their network (see Figure 3 for a summary). The average network size is 4.9 and participants listed up to 15 members. Importantly, 11 participants indicated that they have no group assignment network. While the absence of a network may be expected among first semester juniors as five listed zero network members, the other six students with zero network members were second semester juniors and seniors.

Figure 3: Size of Group Assignment Networks

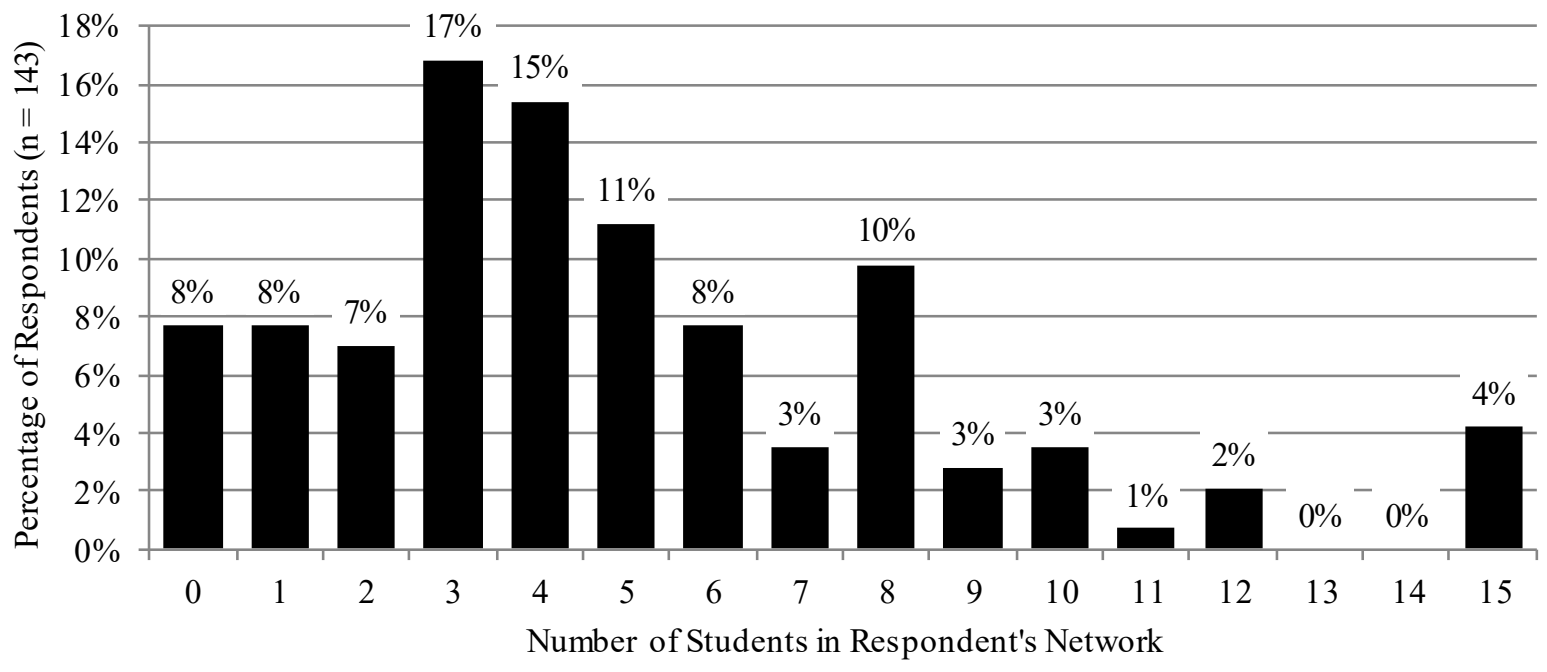

Figure 4: Average Size of Network by Class Standing (bars indicate insignificant differences)

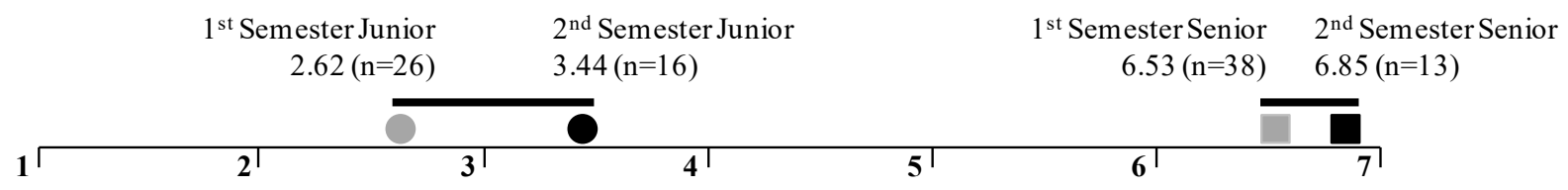


Analysis of variance results show significant group differences in network size based on class standing $[F(3,89)=11.57, p<.001$, Eta squared $=.28]$. As shown in Figure 4, four groups were considered in the analysis: first and second semester juniors, and first and second semester seniors. The average network sizes for the college seniors (6.53 for first semester and 6.85 for second semester) were about double the size of the average network for first and second semester college juniors, with average network sizes of 2.62 and 3.44, respectively. Post-hoc analysis using Tukey HSD (alpha $=.05)$ showed that the cross-class differences between juniors and seniors were significant. However, the differences in network size within classes - between first and second juniors and between first and second semester seniors-were not significant as shown by black bars in Figure 4.

Having found evidence for the existence and growth over time of team assignment networks, analysis turned toward investigating whether students in these networks are tied by trust and beliefs about trustworthiness (research question 4). Average scores for trust and the three dimensions of trustworthiness were calculated for six groups (Figure 5). Three groups were network members - the first, second, and last person each participant listed in his or her network, and three groups were non-network members - one classmate toward whom the subject was indifferent about approaching during team formation, a classmate they would tend to avoid, and a classmate they would tend to approach during the self-selection process. 
Figure 5: Trust and Trustworthiness of Network and Non-Network Members

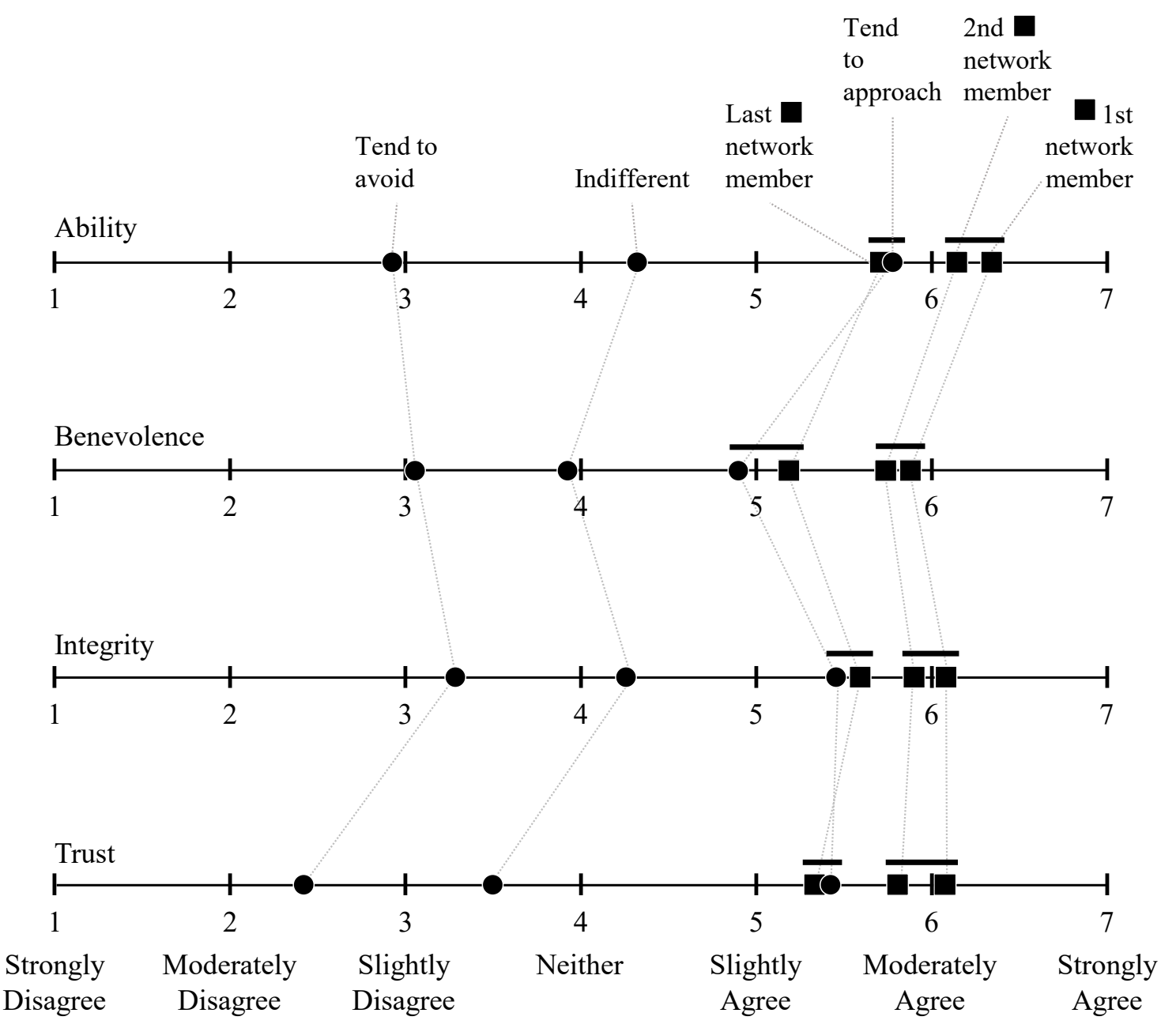

A repeated measures ANOVA with a Greenhouse-Geisser correction was used to test for differences. The Greenhouse-Geisser correction was used since the Mauchly’s Test for Sphericity indicated that the assumption of sphericity was violated. The $F$ statistics were as follows: ability, $F(3.3,243.4)=169.99, p<.001$; benevolence, $F(3.4,254.6)=111.65, p<.001$; integrity, $F(3.4,251.2)=106.53, p<.001$; and trust, $F(2.9,213.5)=141.53, p<.001$. Complete ANOVA results appear in Table 2 in the Appendix. 
Analysis of pairwise comparisons of factor level means is also shown in Figure 5 (using the Bonferroni multiple comparison procedure, alpha $=.05)$. The solid lines between the averages of the $1^{\text {st }}$ and $2^{\text {nd }}$ network members indicate that there is no statistically significant difference in the degree to which they are trusted and believed to be trustworthy. The figure also shows that the last network member is not significantly different from the non-network classmate who students would tend to approach. Together, these homogeneous subgroups of students-last network member and the non-network member to approach — are slightly lower in trust and trustworthiness than the first two network members. The most notable differences in trust and trustworthiness appear between the four most trusted classmates (all three network members and the non-network classmate who students would tend to approach) and the other two classmatesthe one students would tend to avoid and the one towards whom students are indifferent.

Finally, data were summarized to indicate the extent to which students form teams with classmates who are network members (research question 5). In two of the classes surveyed, participants were asked for the number of network members who were in the class. They were also asked to indicate the likelihood of forming a four-person team with one, two, or three of those network members if asked to form a team for an assignment (the class did not have an actual team assignment). As shown in Figure 6, most participants indicated that they definitely would team up with members of their network. In a third class, participants actually completed a team assignment for which they self-selected team members. In this class, participants were asked to indicate the number of network members in the class and whether they formed a team with those members. As shown in Figure 7, 15 of 20 respondents reported having one or more network members in the class and 10 of the 15 filled their team with the maximum number of 
network members. That is, six students formed their four-person team with three network members and four students teamed up with the one other network member in the class.

Figure 6. Likelihood of Forming a Group with Network Members Who Are in Class

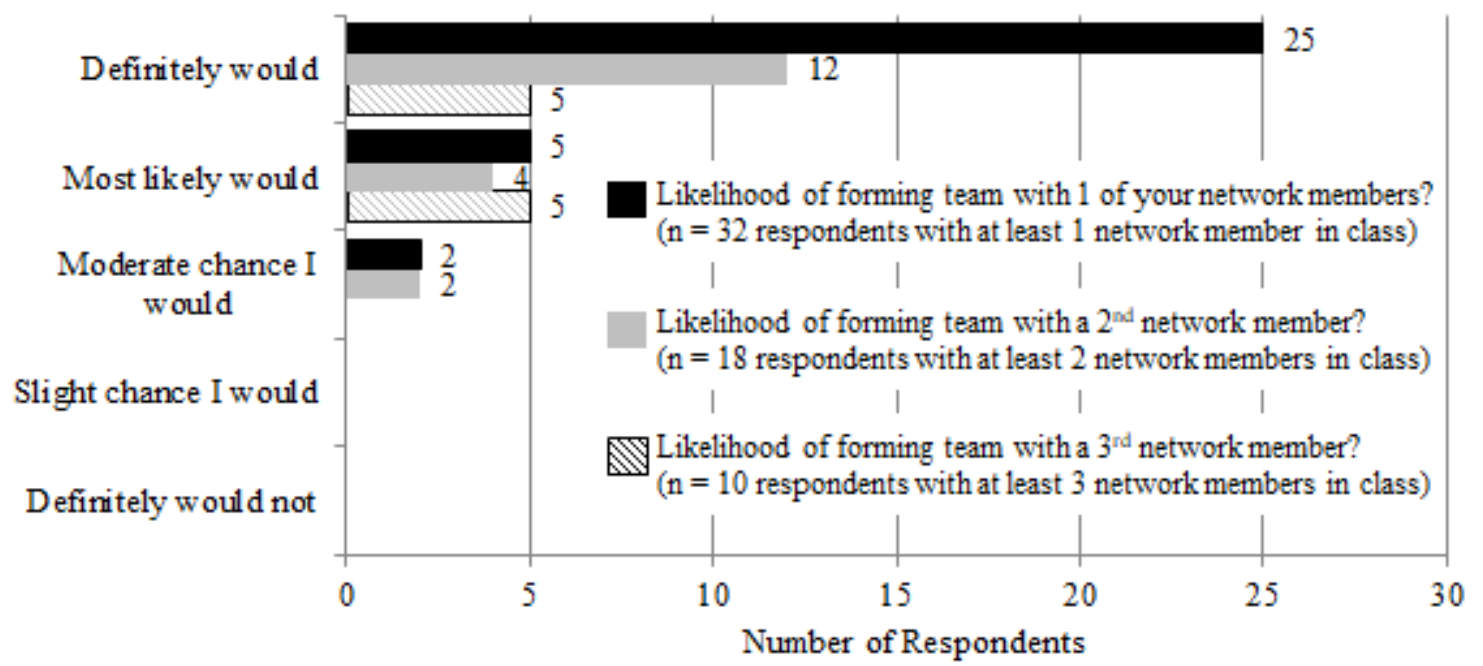

Figure 7. Extent to Which Students Teamed Up with

Group Assignment Network Members

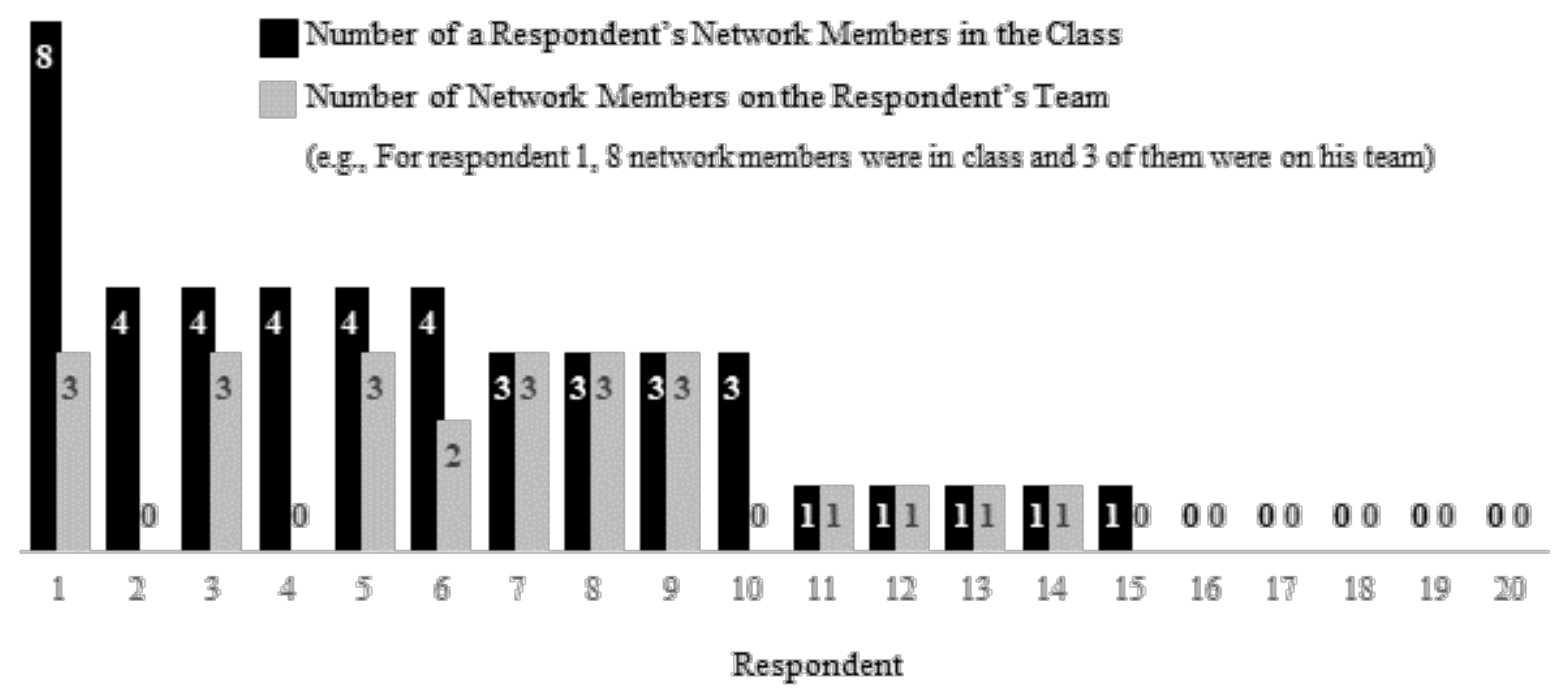




\section{Discussion for Study 1}

This first study revealed that self-selecting teams motivates students to engage in a process of cognitively categorizing their classmates as those to approach and those to avoid, and students put forth a good deal of effort to actually approach some classmates and avoid others. This study also provides evidence that the approach category forms for most students as they develop a type of team assignment social network comprised of classmates who are believed to be high on all three dimensions of trustworthiness — ability, benevolence, and integrity. Network members are highly trusted classmates and the ones with whom students actually do or would team up given the opportunity to self-select their team.

These findings should be relevant to instructors because a main implication of social networks is that network members have access to social capital-e.g., abilities of other members - and thus realize benefits by virtue of membership in a network (Van den Bulte \& Wuyts, 2007). Recall that network members were rated quite high on the abilities dimension of trustworthiness. Since network members were listed by name and thus familiar to subjects in this study, they may be relatively high in abilities. If so, when students team up with network members they have access to social capital in the form of abilities that others may bring to bear on the project such as the ability to be an effective member of a work team, project relevant skills, or knowledge and cognitive abilities (Neu, 2015). Students could then realize the benefit

of higher performance on the project, and thus a higher grade, simply by virtue of membership in a network.

Students may also accrue benefits from having a network comprised of classmates who rate high on the other two dimensions of trustworthiness. That is, if a student teams up with others who are high in benevolence, he or she likely accrues the benefits of working with team 
members who are helpful and look out for the best interests of others. When a student teams up with others who are high in integrity, he or she likely enjoys the benefits of working with team members whose behavior is guided by an acceptable level of value placed on education, grade, and contributing one's fare share in terms of quantity and quality of work. And, by teaming up with network members who are relatively high on all three dimensions of trustworthinessability, benevolence, and integrity—students very likely realize more of the positive emotional consequences and fewer of the negative emotional consequences that are commonly associated with team assignments (Neu, 2012).

A key point is that while social capital likely accrues to students by virtue of membership in a group assignment network, the extent to which social capital and thus benefits accrue depend on the nature of the network (Van den Bulte \& Wuyts, 2007). Study 1 indicates that students do differ significantly in network size, the consequence of which is that some students have greater access to social capital and thus realize more benefits than others. As previously mentioned, some students reported having no network at all and others reported up to 15 members, and juniors were shown to have smaller networks on average than seniors. The fundamental issue is that self-selection may facilitate inequity among students simply due to the disparity in the size or makeup of their group assignment social networks.

One of the most notable findings in Study 1 is that there are situations when a classmate is not included in a student's team assignment network, but the classmate is trusted and thought to be as trustworthy as a network member. While trust and trustworthiness of a non-network classmate could form in different ways, prior qualitative research (Neu, 2012; 2015) suggests that, in the absence of prior knowledge, students rely on social cues to form initial beliefs about their classmates' trustworthiness and then approach or avoid them during team formation based 
on those beliefs. The influence of social cues in the self-selection process then provided the focus of Study 2.

\section{Study 2}

\section{Background and Hypotheses}

The high level of trustworthiness and trust that tie students in their team assignment network likely form, in large part, in a developmental way (Jones \& George, 1998). That is, trust likely develops over time as students interact with and learn about each other. But trust/distrust does not only develop over time as people interact with each other; instead, individuals sometimes began an encounter with strangers and have varying degrees of initial trust. Initial trust between parties is not based on direct experience or firsthand knowledge of the other party. Instead, it emerges initially from three antecedent conditions (McKnight, Cummings, \& Chervany, 1998).

First, initial trust depends on personality; people simply differ in their general disposition to trust/distrust. If no other situational information is available, one will rely on one's general belief that nonspecific individuals can be trusted (Wrightsman, 1991). Second, institution-based trusts involves the belief that impersonal structures-e.g., regulations, guarantees, legal recourse - are in place and mitigate the perceived risk in forming a trusting relationship. Third, trust can emerge from three types of social categorization processes: unit grouping, reputation, and stereotyping (McKnight, Cummings, \& Chervany, 1998).

Unit grouping is a phenomenon through which a member of a group tends to have initial trust in others who are also members of the same group. Initial trust due to reputation is a process by which an individual who has a positive reputation-e.g., via being a member of a competent group or word-of-mouth (Dasgupta, 1988) — will tend to be categorized by others as one who can be trusted. And, initial trust can arise from stereotyping. While unit grouping and reputation 
require prior knowledge of the other party, trust due to stereotyping involves no prior knowledge. Instead, it is a fundamental cognitive process during which one is exposed to stimuli in the form of social cues_-behaviors and traits — that are present when parties meet or interact. People then use the social cues to cognitively categorize others and make inferences about them based on the category in which they are placed (Schneider, 2004). In other words, stereotyping is a social categorization process used to "fill in the blanks" when faced with a lack of information about others.

Students are, at times, faced with the cognitive problem of self-selecting teams while having no prior knowledge about their classmates. That is, students will have no prior experiences through which they have interacted with and learned about each other, nor will they have knowledge about each other's group membership or reputation. When faced with this situation, it is expected that students will use social cues to categorize classmates and make inferences about their trustworthiness based on the category in which they are place. In addition, since beliefs about trustworthiness have been consistently shown to be the main precursor to trust (Mayer et al., 1995), is also expected that students' level of trust in classmates will depend on social cues. And, since trust precedes risk-taking behavior (Mayer et al., 1995), it is expected that students' preferences for team membership and the extent to which they will approach or avoid others during the team formation process will also depend on social cues. More formally, given no prior knowledge of classmates:

H1: Students' beliefs about their classmates' trustworthiness depends on social cues.

H2: Students' trust in their classmates depends on social cues. 
H3: Students' preference for having/not having a classmate on a team depends on social cues.

H4: Students' behavioral intentions to approach/avoid classmates during team formation depends on social cues.

\section{Methodology}

One hundred ninety undergraduate business students were recruited from six sections of an introductory marketing class. Students were from a variety of business majors and $57 \%$ were juniors, $36 \%$ were seniors, and $7 \%$ identified their class standing as "other. The final sample consisted of 160 usable surveys since 30 surveys were removed due to incompleteness, extreme acquiescence or social desirability bias (all survey responses for trust and trustworthiness were neutral), or correctly explaining the purpose of the study.

Subjects were assigned to one of five treatments and all subjects completed a selfadministered survey that started with the following scenario.

Assume that you are attending the first day of a marketing class. The class meets Monday and Wednesday from 5:00 PM to 6:50 PM. While covering the course syllabus your instructor explains that you will complete a semester-long project in teams of four. The assignment is to develop a marketing strategy for a local coffee shop. The project requires applying a broad range of course content, conducting original library research, and completing data analysis in Excel.

Your team will submit one formal written report that is 20 to 25 pages in length.

Your team will also develop and deliver to the rest of the class a 15 minute formal oral presentation and your presentation visuals will need to be developed in PowerPoint. 
The project is worth $50 \%$ of your course grade (report worth $35 \%$ and presentation worth 15\%). Your team will be given one grade for the paper and one grade for the presentation; all team members will receive the same grades. Your instructor also explains that you need to form your own team before the next class meeting.

The second page then stated, "Now assume that you are in the process of forming your team. You also find that all classmates are unfamiliar to you — you don't know any of them and have never had them in a class before. One of your classmates is the individual shown below." Immediately following this statement was one of the five images that appear in Figure 8 . The images were obtained from an on-line stock photo site. The model, who appears in image 4 in Figure 8, was then "redressed" in Photoshop using parts of other images.

Following the image were survey items to measure beliefs about the trustworthiness of, and level of trust in, the person shown in the image. The measures of trust and trustworthiness used in Study 1 were also used for this part of the research. Scale reliabilities (alpha) were ability $=.91$, benevolence $=.82$, integrity $=.84$, and trust $=.88$. In addition, one seven-point item was used to gauge subjects' preference for not wanting/wanting the individual in the image on his or her team and responses ranged from definitely do not want him on my team to definitely want him on my team. And, one seven-point item asked subjects to indicate the extent to which they would avoid or approach the individual shown in the image to ask him to be on his or her team; responses ranged from putting forth a high effort to avoid to a high effort to approach the individual in the image.

Data were gathered during the last $15-20$ minutes of each class. Since the five versions of the survey contained a different image, the instrument was distributed by row to minimize the 
chance that subjects could see the images in different versions of the instrument. As such, each subject's neighbors seated directly to his or her left and right had the same image (were in the same treatment), and those seated to the back and front had a different image (were in different treatments). The versions of the survey were organized in sets that had been place in a random order prior to entering the classroom. Sets of surveys were then distributed by row starting at the back of the room. Treatment sample sizes also appear in Figure 8.

\section{Figure 8. Images Used for Different Treatments}
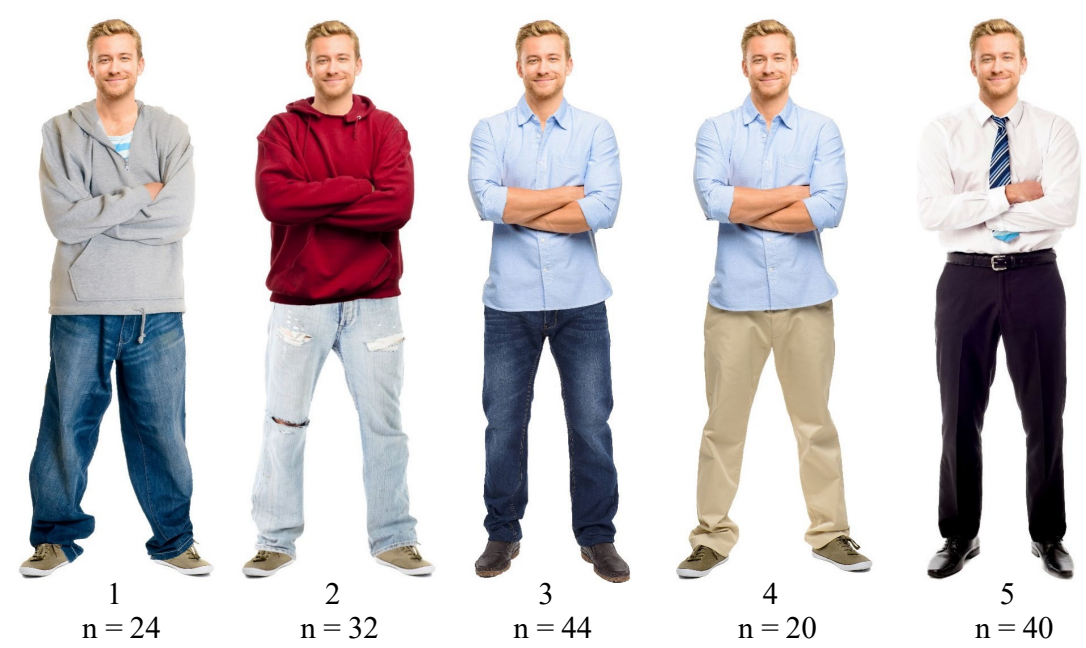

\section{Results}

Differences among treatments were assessed using a one-way ANOVA (treatment averages are displayed in Figure 9 and complete results appear in Table 3 in the Appendix). In support of Hypothesis 1, results indicate a difference among treatments on beliefs about trustworthiness, and the most significant differences are in beliefs about ability $[F(4,155)=8.24, p<.001]$. Results also indicate a difference among treatments in beliefs about benevolence $[F(4,155)=$ $2.76, p=.030]$ and integrity $[F(4,155)=3.40, p=.011]$. In support of Hypothesis 2, results also reveal a significance difference among treatments on trust $[F(4,155)=5.65, p<.001]$. Post hoc 
analysis using the Tukey HSD test $(a l p h a=.05)$ revealed the homogeneous subgroups that are indicated by black bars in Figure 9.

Figure 9. Factor Level Means for Trustworthiness and Trust

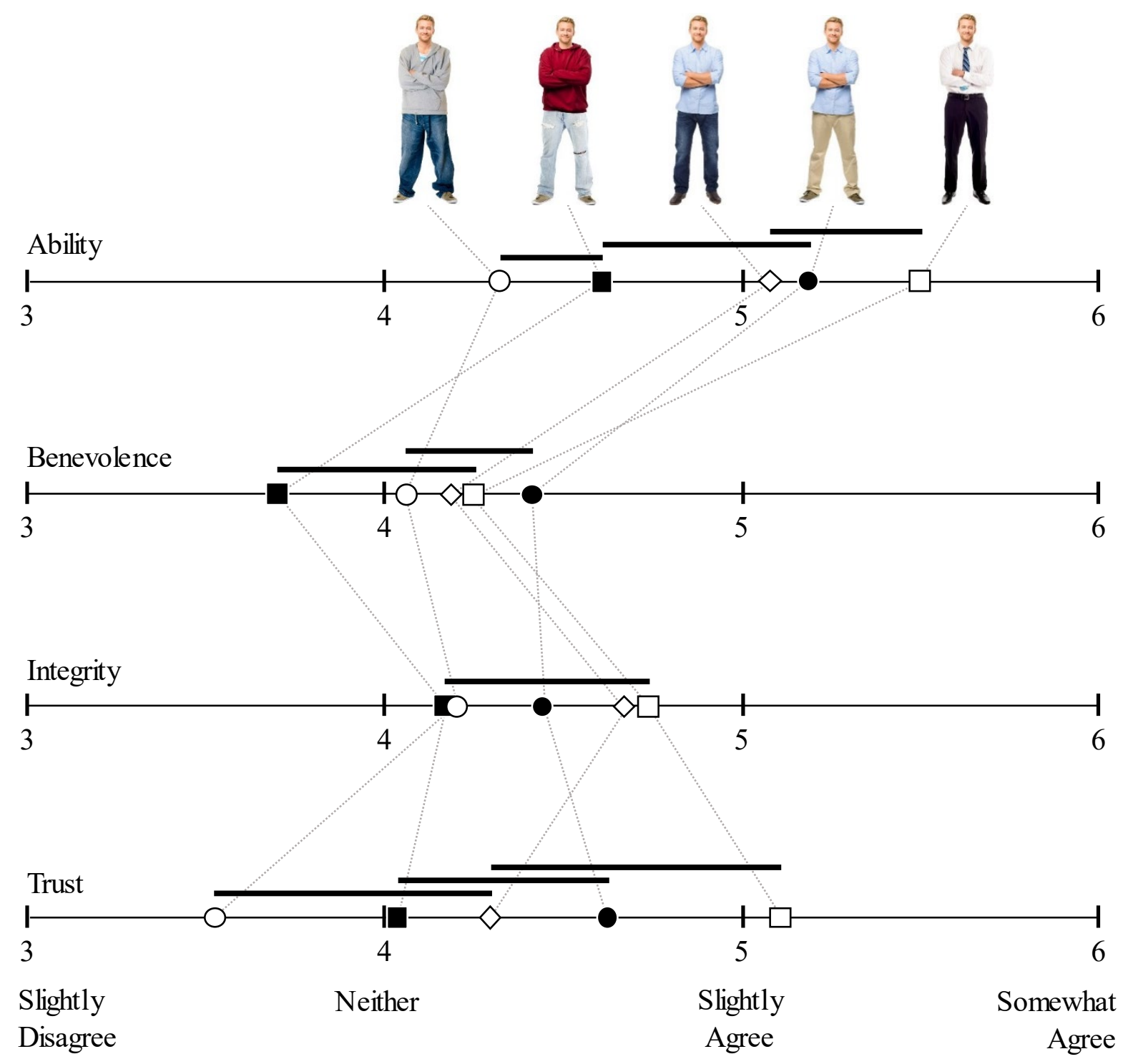

In support of Hypotheses 3, there is also a statistically significant difference in preference for not wanting/wanting the classmate on a team $[F(4,153)=9.83, p<.001]$. In addition, treatments differ on the extent to which subjects think they would put forth effort to avoid or approach the classmate to ask him to be on their team in support of Hypothesis $4[F(4,153)=$ 
$14.95, p<.001]$. Treatment means and homogeneous subgroups, based on the Tukey HSD test with alpha $=.05$, are shown in Figure 10.

Figure 10: Factor Level Means for Not Want/Want on Team and

Effort to Avoid/Approach
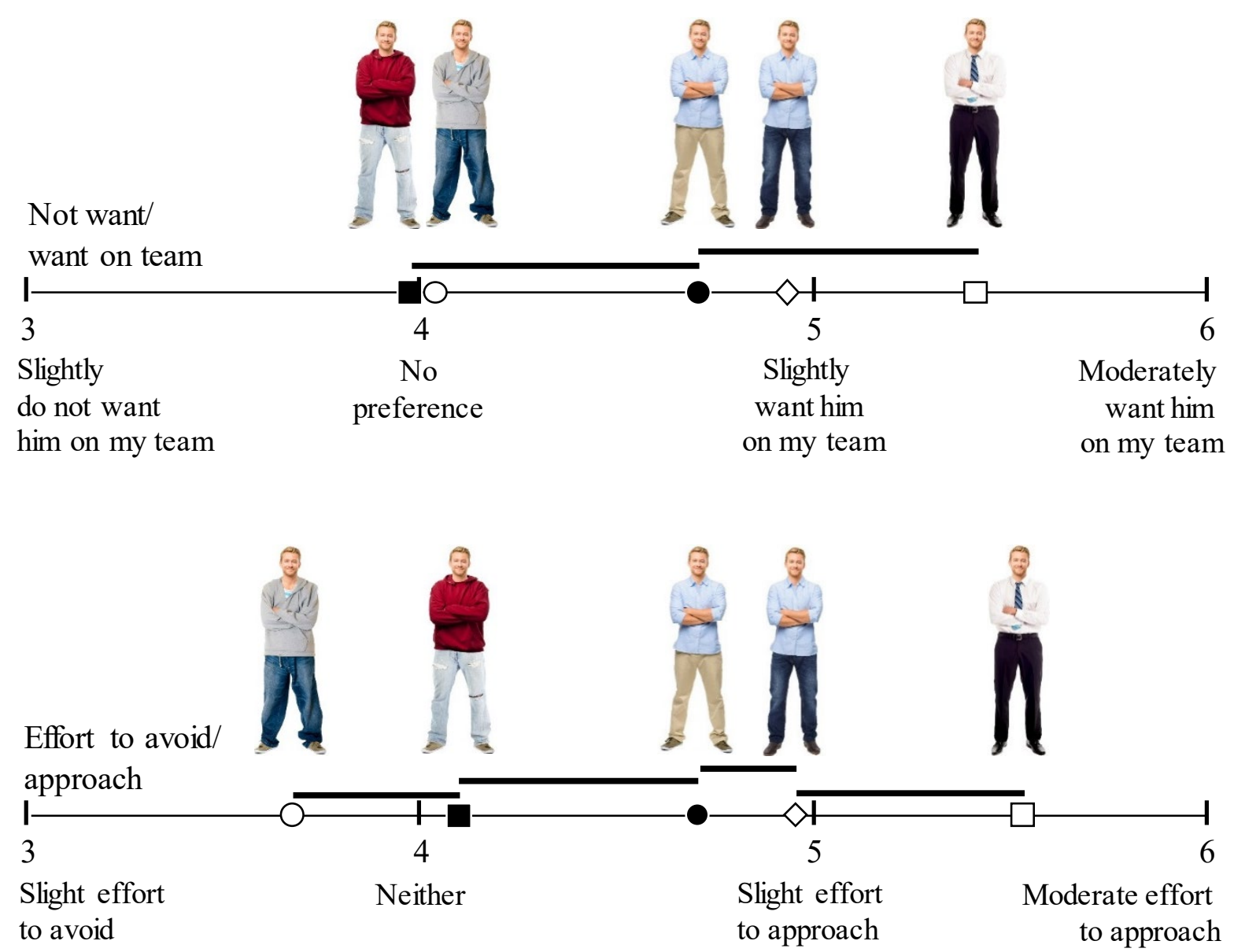

\section{Discussion for Study 2}

Study 1 reported that students place a high level of importance on cognitively categorizing their classmates as those to approach and avoid when self-selecting teams. Study 2 then indicates that, when faced with the problem of having no prior knowledge about classmates, 
students use social cues to cognitively organize their classmates and make inferences about them based on the category in which they are placed.

One main cognitive group appears to be comprised of students who fit what has been referred to as the B-school norm (Neu, 2015). While students may use several social cues, or identifying features (Schneider 2004), to identify B-school norm membership, this study featured B-school casual clothes, a style of dress that has been defined as moderate, conservative, coordinated, clean, ironed, and good-fitting (Neu, 2015). Images 3 and 4 in Figure 8 reflect a student who is wearing B-school casual clothes and thus the images represent a member of the B-school norm category.

A second broad category of classmates appears to be comprised of those who are excluded from the B-school norm because one or more social cues deviate too far from the norm. Images 1 and 2 in Figure 8 reflect a style of dress that is too atypical (at least in the context of this study), and thus a classmate who is excluded from the B-school norm. The classmate is then inferred to be relatively low in trustworthiness and trust and, in turn, he is a less preferred team member and more likely to be avoided during team formation.

This study also suggests that students use style of dress to cognitively separate some classmates from the B-school norm category and place them in a student/working professional category. That is, the identifying feature (style of dress) is not consistent with one who is "just" a student, but instead represents a classmate who also has a professional job. The classmate in this category is then inferred to be relatively high in trust and at least on the abilities dimension of trustworthiness. He is also a preferred team member and a classmate to approach during team formation. 
A main point is that when asked to self-select team members, students tend to use social cues (styles of clothes) to cognitively categorize their classmates and make inferences about their trustworthiness based on the category in which they are placed. And, making inferences about a social category of people, or individuals in the category, is stereotyping (e.g., Schneider, 2004). While the style of dress tested in this study did not induce negative beliefs about trustworthiness (the lowest ratings were close to neutral), it did have a positive effect and was influential enough to raise beliefs about the abilities of a completely unfamiliar classmate to a level similar to network members. That is, the abilities of an unfamiliar student wearing dress slacks and a tie in Study 2 (average $=5.49)$ are believed to be on par with the last network member listed in Study 1 (average $=5.73)$

This study also indicates that social categorization based on style of dress influences students' preference for who they want on their team and the effort they would put forth to approach some classmates and avoid others. Similar to beliefs about trustworthiness, style of dress did cause an effect on both preference and intent to approach or avoid. Specifically, wearing B-school casual clothes (images 3 and 4) or business-like clothes (image 5) caused a shift from being indifferent to having a positive preference for wanting the classmate on a team. Regardless of being a positive or a negative effect, a preference for wanting a classmate on a team is an affective response, and affective responses toward a social group of people, or individuals in the group, is prejudice (Schneider, 2004). Finally, approaching some classmates and avoiding others based on the social category in which they are placed, rather than on individual merit, is discrimination (Schneider, 2004). While students didn't actually engage in avoidance/approach behaviors and thus did not actually discriminate, they did report their intentions to do so. 


\section{Conclusion}

In a study by Hart Research Associates (2010), employers selected teamwork skills and the ability to collaborate with others in a diverse group setting as one of top five intellectual and practical skills that colleges should place greater emphasis on (Hart Research Associates, 2010). The ability to work effectively with others in a team was again reported as a top learning outcome in 2015 (Hart Research Associates, 2015). In the same 2015 study, Hart Research Associates found that $96 \%$ of employers either somewhat or strongly agree with the statement, "All students should have experiences in college that teach them how to solve problems with people whose views are different from their own" (Hart Research Associates, 2015). At the same time, just $18 \%$ of respondents in the 2015 Hart study indicated that college graduates are well prepared to work with people who are different. In two fundamental ways this research suggests why.

First, developing students' ability to work with people who are different requires engaging with others who are different; students need to be exposed to diversity (Buchar 2015). As shown in Study 1, students tend for form and team up with members of a team assignment social network, and prior research indicates that people tend to form social networks with others who are similar (McPherson, Smith-Lovin, \& Cook, 2001). Therefore, if students routinely selfselect teammates from their team assignment network they may be routinely teaming up with classmates who are similar which would, in turn, impede exposure to diversity and the development of diversity skills. Interestingly, students who either do not have a group assignment social network or have one that is limited in size may find themselves teaming up with a more diverse collection of classmates, and having more opportunities to develop diversity skills than students who have a well-developed network. 
Second, Study 2 found that self-selection places students in situations that perpetuate what Buchar (2015) explains as three of the main barriers to developing diversity skills: stereotyping, prejudice, and discrimination. When students stereotype their classmates they place them in a cognitive group and infer them to be similar to others in the group and, at the same time, they infer them to be different from classmates in other groups. When students use such an oversimplified generalization about a group of classmates they ignore and devalue individual differences which constrain the ability to relate effectively with others (Buchar 2015). Also, when students experience prejudice and then actually discriminate or avoid certain groups of classmates, they limit their exposure to others who are different which constrains their development of diversity skills.

If business schools are to prepare graduates to work effectively with diverse people, they need to provide students with ample opportunities to engage with others who are different. If team assignments are intended to provide such opportunities, then instructors should adopt approaches to group students with others who are in fact different (e.g., see CATME at www.catme.org). In addition, instructors should recognize that stereotyping, prejudice, and discrimination are among the main barriers to developing diversity skills. And, if instructors intend to help prepare graduates to work effectively with diverse people, they are encouraged to reflect on the extent to which their curriculum is aimed at helping students overcome such barriers and consider adopting learning experiences that do so (e.g., see Buchar, 2015; Rosenbaum, Moraru, \& Labrecque 2014).

\section{Limitations and Future Research}

As with any research this study is not without its limitations, some of which provide opportunities for future research. Study 1 was exploratory in nature and was aimed at clarifying 
the nature and extent to which students form a type of team assignment social network. While the study does provide evidence of team assignment networks, additional research could be directed at clarifying the extent to which students form a network that is specific to team assignments and that it is distinct from other social networks in which a student may be embedded (e.g., a friendship network).

There is also a need to further investigate the benefits that accrue to students by virtue of membership in a team assignment social network. Benefits that are worth investigating include consequences of interest to students such as a higher final grade on the team's deliverable, equity in quantity and quality of work provided, and an increase in positive emotions or reduction in negative emotions that students associate with team assignments. Relatedly, there is a need to understand the disparity among students in the size and makeup of their social networks, and the attributes (e.g., race, age, personality type, knowledge of the value of networks and how do develop them) that explain the disparities. Doing so would shed light on the extent to which certain groups of students are at an advantage or a disadvantage due to the extent and makeup of their network. More broadly, doing so could give direction for how to help students develop social networks, an ability that is considered key to successful professional development but rarely taught in business schools (Misner, 2017). And, for number of reasons, emphasis should be on learning experiences that help students expand the diversity of their social networks (Buchar, 2015).

Study 2 was limited to one social cue and provided some insight into the social categories in which classmates are placed. There is a need to further understand the social categorization process in terms of the categories in which students cognitively place their classmates and the defining features of those categories. That is, if classmates are excluded from the B-school norm 
category are they actually placed in one of several other categories and, if so, what are the cognitive, affective, and behavioral consequences — positive and negative — associated with the categories.

Study 2 was also limited to one mode of team formation-pure self-selection. As such, there is a need to understand what actually occurs when instructors share decision-making authority with students. Specifically, research should clarify the extent to which students engage in social categorization and stereotyping prior to indicating their preference for who they do and do not want to work, and the degree to which stereotyping influences students' decisions when they are required to select team members given certain constrains (e.g., at least one international student on a team). Regardless of the process through which teams are formed, research should be directed at understanding the extent to which social categorization and stereotyping precede other risk-taking behaviors after teams have been formed. For example, students inevitably partition a team assignment into a number of discrete units of work, and then make decisions about who is responsible for each unit. Prior research indicates that units of work are sometimes allocated based on beliefs about trustworthiness (Neu 2012), and when a team member is thought to be relatively low in trustworthiness other members may not be willing to assign the student "important" units of work. As such, there is a need to understand the extent to which stereotyping influences the allocation of units of work during a team assignment, or the assignment of distinct team member roles that students perform (e.g., being the team leader). Such a consequence would directly influence student learning and development and could be present regardless of the way in which teams are formed. 


\section{Appendix}

\section{Table 1: Indicators of Trustworthiness and Trust}

\begin{tabular}{l|l}
\hline Ability 1 & The $\mathbf{1}^{\text {st }}$ person I listed would be very capable of performing his/her job. \\
\hline Ability 2 & This person is very successful at the things he/she tries to do. \\
\hline Ability 3 & This person has specialized capabilities that could increase a team's performance. \\
\hline Ability 4 & This person would be very concerned about my welfare. \\
\hline Benevolence 1 & My needs and desires would be very important to this person. \\
\hline Benevolence 2 & This person would not knowingly do anything to upset me. \\
\hline Benevolence 3 & This person would go out of his/her way to help me. \\
\hline Benevolence 4 & This person would try hard to be fair in dealings with others. \\
\hline Integrity 1 & Very sound values would guide this person's behavior. \\
\hline Integrity 2 & I would be very comfortable giving this person a task that is critical to me, even if I could not \\
Integrity 3 & monitor his/her actions. \\
\hline Trust 1 & I would be very comfortable letting this person work on a key part of a team assignment, even \\
if all team members are given the same final project grade.
\end{tabular}

Table 2: ANOVA Results for Study 1

\begin{tabular}{|c|c|c|c|c|c|c|c|}
\hline & & $\begin{array}{c}\text { Type III } \\
\text { Sum of Squares } \\
\end{array}$ & df & Mean Square & $\mathbf{F}$ & Sig. & $\begin{array}{c}\text { Partial } \\
\text { Eta Squared } \\
\end{array}$ \\
\hline Ability * & Between Groups & 654.6 & 3.3 & 199.01 & 166.99 & $<.001$ & .69 \\
\hline Group & Within Groups & 290.1 & 243.4 & 1.19 & & & \\
\hline Benevolence * & Between Groups & 448.0 & 3.4 & 130.22 & 111.65 & $<.001$ & .60 \\
\hline Group & Within Groups & 296.9 & 254.6 & 1.17 & & & \\
\hline Integrity * & Between Groups & 443.1 & 3.4 & 130.52 & 106.53 & $<.001$ & .59 \\
\hline Group & Within Groups & 307.8 & 251.2 & 1.23 & & & \\
\hline Trust * & Between Groups & 806.5 & 2.9 & 279.53 & 141.53 & $<.001$ & .66 \\
\hline Group & Within Groups & 421.7 & 213.5 & 1.98 & & & \\
\hline
\end{tabular}


Table 3: ANOVA Results for Study 2

\begin{tabular}{|c|c|c|c|c|c|c|c|}
\hline & & Sum of Squares & df & Mean Square & $\mathbf{F}$ & Sig. & Eta Squared \\
\hline Ability * & Between Groups & 26.6 & 4 & 6.64 & 8.24 & $<.001$ & .18 \\
\hline Group & Within Groups & 124.9 & 155 & 0.81 & & & \\
\hline Benevolence * & Between Groups & 8.4 & 4 & 2.11 & 2.76 & .030 & .07 \\
\hline Group & Within Groups & 118.5 & 155 & 0.77 & & & \\
\hline Integrity * & Between Groups & 9.4 & 4 & 2.35 & 3.40 & .011 & .08 \\
\hline Group & Within Groups & 107.1 & 155 & 0.69 & & & \\
\hline Trust * & Between Groups & 44.5 & 4 & 11.14 & 5.65 & $<.001$ & .13 \\
\hline Group & Within Groups & 301.4 & 153 & 1.97 & & & \\
\hline Want on team * & Between Groups & 49.5 & 4 & 12.36 & 9.83 & $<.001$ & .21 \\
\hline Group & Within Groups & 192.4 & 153 & 1.26 & & & \\
\hline Effort to approach * & Between Groups & 67.3 & 4 & 16.82 & 14.95 & $<.001$ & .28 \\
\hline Group & Within Groups & 172.1 & 153 & 1.13 & & & \\
\hline
\end{tabular}




\section{References}

Bacon, D. R., Stewart, K. A., \& Stewart-Belle, S. (1998). Exploring predictors of student team project performance. Journal of Marketing Education, 20(1) 63-71.

Bacon, D. R., Stewart, K. A., \& Anderson, E. S. (2001). Methods of assigning players to teams: A review and novel approach. Simulation \& Gaming, 32(1), 6-17.

Blowers, P. (2003). Using student skill self-assessment to get balanced groups for group projects. College Teaching, 50(3), 106-110.

Boss, R. W. 1978. Trust and managerial problem solving revisited. Group and Organization Studies, (3) 331-342.

Buchar R. D. (2015). Diversity consciousness: Opening our minds to people, cultures, and opportunities. New York, NY: Pearson.

Chapman, K., Meuter, M., Toy, D., \& Wright, L. (2006). Can't we pick our own groups? The influence of group selection method on group dynamics and outcomes. Journal of Management Education, 30(4), 557-569.

Connerley, M. L., \& Mael, F. A. (2001). The importance and invasiveness of student team selection criteria. Journal of Management Education, 25(5), 471-494.

Dasgupta, P. 1988. Trust as a commodity. In D. Gambetta (Ed.), Trust: Making and breaking cooperative relations: 47-72. New York: Basil Blackwell.

Feichtner, S. B., \& Davis, E. A., (1985). Why some groups fail: A survey of students' experiences with learning groups. Journal of Management Education, 9(4), 77-88.

Hart Research Associates (2010). Raising the bar: Employers' views on college learning in the wake of the economic downturn.

Hart Research Associates (2015). Falling short? College learning and career success. 
Huxham, M., \& Land, R. (2000). Assigning students in group work projects: Can we do better than random? Innovation in Education and Training International, 37(1), 17-22.

Jalajas, D. S., \& Sutton, R. I. (1984-1985). Feuds in student groups, coping with whiners, martyrs, saboteurs, bullies, and deadbeats. Organizational Behavior Teaching Review, 9(4), 217-227.

Jones, G. R. \& George, J. M. (1998). The Experience and Evolution of Trust: Implications for Cooperation and Teamwork. The Academy of Management Review, 23(3), 531-546

Mayer, R. C., Davis, J. H., \& Schoorman, D. F. (1995). An integrative model of organizational trust. Academy of Management Review, 20, 709-734.

Mayer, R. C., \& Davis, J. H. (1999). The effect of the performance appraisal system on trust for management: A field quasi-experiment. Journal of Applied Psychology, 84(1), 123-136.

Mayer. R. C. \& Gavin, M. B. (2005). Trust in management and performance: Who minds the shop while the employees watch the bass? Academy of Management Journal, 48(5), 874888.

Matta, V., Luce, T., \& Ciavarro, G. (2010). Exploring impact of self-selected student teams and academic potential satisfaction. Proceedings of the Information Systems Educators Conference, 27(1304), 1-10.

McKnight, D. H, Cummings, L. L. \& Chervany, N. L. (1998). Initial trust formation in new organizational relationships. Academy of Management Journal, 23(3), 473-490.

McPherson, M., Smith-Lovin, L., \& Cook, J. M., (2001). Birds of a feather: Homophily in social networks. Annual Review of Sociology. 27, 415-444.

Mello, J. A. (1993). Improving individual member accountability in small work group settings. Journal of Management Education, 17(2), 253-259. 
Misner, I. (2017). Networking like a pro: Turning contacts into connections. Irvine, CA: Entrepreneur Press.

Muller, T. E. (1989). Assigning students to groups for class projects: An exploratory test of two methods. Decisions Sciences Journal, 4, 623-634.

Neu, W. A. (2012). Unintended cognitive, affective, and behavioral consequences of group graded assignments. Journal of Marketing Education, 34(1) 67-81.

Neu, W. A. (2015). Social cues of (un)trustworthy team members. Journal of Marketing Education, 37(1) 36-53.

Rosenbaum, M. S., Moraru, I., Labrecque, L. I. (2014). A multicultural service sensitivity exercise for marketing students. Journal of Marketing Education, 35(1), 5-17.

Schneider, D. J. (2004). The psychology of stereotyping. New York, NY: The Guilford Press.

Scott, T. J., Bisland, R. B., Tichenor, L. H., \& Cross, J. H. (1994). Team dynamics in student programming projects. Proceedings of the Twenty-Fifth SIGCSE Symposium on Computer Science Education, 26(1), 111-115.

Seethamraju, R., \& Borman, M. (2009). Influence of group formation choices on academic performance. Assessment \& Evaluation in Higher Education, 34(1), 31-40.

Thorndike, E. L. (1906). Introduction. In The principles of teaching: Based on psychology (pp. 111). New York, NY: A. G. Seiler.

Van den Bulte, C. \& Wuyts, S. (2007). Social networks and marketing. Cambridge, MA: Marketing Science.

Wrightsman, L. S. (1991). Interpersonal trust and attitudes toward human nature. In J. P. Robinson, P. R. Shaver, \& L. S. Wrightsman (Eds.), Measures of personality and social psychological attitudes (pp. 373-412). San Diego: Academic Press. 
Zand, D. E. (1972). Trust and managerial problem solving. Administrative Science Quarterly. (17) 229-239.Tab 